\title{
Innovative Tools of Sustainable Mobility in European Urban Areas: Experience with Evaluation and Role of Political Barriers
}

\author{
H. Brůhová-Foltýnová*, R. Jordová \\ Transport Research Centre - CDV, Líšeňská 33a, Brno \\ *Corresponding author: hana.bruhova@cdv.cz
}

DOI: $10.2478 /$ trans-2014-0011

\begin{abstract}
The presented article describes a European initiative for supporting innovative measures in sustainable transport in urban areas Civitas, particularly its latest completed edition Civitas Plus (2008-2012). The article presents the evaluation process of the performed measures and shows an overview of the main obstacles the Civitas Plus cities struggled with (with the emphasis on political barriers). In addition, it mentions drivers which helped to implement the sustainable mobility measures. It concludes with examples from European cities on how to avoid these barriers and prevent their occurrence.
\end{abstract}

KEY WORDS: Civitas initiative, political barriers, evaluation of sustainable mobility measures.

\section{INTRODUCING THE CIVITAS INITIATIVE}

It is mainly cities and urban areas which bear the negative effects of transport, such as traffic congestion, road accidents, emissions of pollutants and noise, while they can significantly contribute to their reduction. Cities play the major role in economic growth and development they produce approx. 85\% of EU GDP (Bosetti et al., 2014) -, are places where services, business, culture, industry and other functions are located, and furthermore they provide the transport infrastructure. Cities grow and develop, which relates to a large number of landuse problems on different levels, particularly regarding the relationships between cities and their peripheries, or between cities and higher administration units.

Transport and mobility reflect all these activities and the related duality of economic development and the environmental limits. The demand for mobility gradually increases and higher requirements are made of transport supply and deliveries. All these have an impact on the land use of urban areas for the transport infrastructure and also on the transport behaviour of inhabitants. It is clear that transport cannot only be dealt with by satisfying demand; the experience, not only from Czech cities, clearly shows that we are already limited in this respect. The cities do not have sufficient space for building new parking places, serious traffic congestions occur, etc. It is necessary to choose a balanced mixture of measures which should lead to sustainable use of transport with maximum emphasis on the use of alternatives to individual car transport, mobility and traffic flow management.

The European initiative Civitas (City-Vitality-Sustainability) has been supporting European cities for longer than ten years in the implementation of useful measures in all fields of sustainable transport. The European Commission uses this programme to support the spreading of innovative measures and the exchange of experience among EU cities. Since 
2002, the EC has specifically provided financial and organizational support to more than 60 European cities to implement more than 800 measures for EUR 120m, within four consecutive editions (programmes). The latest completed edition took place from 2008 to 2013 with the title Civitas Plus (Brůhová-Foltýnová \& Jordová, 2014a).

So far the funds from CIVITAS have supported transport solutions in three Czech cities Prague, Ústí nad Labem and Brno. The latter two cities were supported by Civitas Plus.

This article describes the evaluation methods of measures of Civitas Plus in terms of their impact as well as the implementation process, and what were the most common barriers and drivers the cities encountered within the implementation of measures. We are to focus in more detail on political barriers and how it is possible to avoid / deal with these barriers on examples from European cities.

\section{EVALUATION PROCESS OF CIVITAS PLUS PROJECTS}

In total, 5 projects in 25 cities were implemented within the edition of Civitas Plus, which altogether made more than 300 measures to sustainable mobility. These measures were evaluated on the basis of their overall effectiveness. The following projects and cities were involved:

- ARCHIMEDES (Aalborg, Brighton \& Hove, San Sebastian, Iasi, Monza, Usti nad Labem);

- ELAN (Ljubljana, Gent, Porto, Brno, Zagreb);

- MIMOSA (Bologna, Funchal, Utrecht, Gdansk, Tallinn);

- MODERN (Craiova, Brescia, Vitoria/Gasteiz, Coimbra);

- RENAISSANCE (Szczecinek, Perugia, Bath, Gorna Oryahovitsa, Skopje).

The implemented measures needed to be innovative and had to extend the existing knowledge and experience of the cities in the field of sustainable mobility. Some of their innovative features are mentioned as follows (Civitas Pointer, 2013a):

- Measures using new tools or methods: $48 \%$ of all measures;

- Measures using new technologies / ITS (real-time information on usage of vehicles, distribution of parking vehicles, intervals of buses and passenger flows or checks of signalling systems adapting to the existing traffic situation): $45 \%$ of all measures,

- Measures focused on specific groups of users (people living close to a bus line or travelling to a certain locality, or drivers of a certain type of vehicle): $39 \%$ of all measures.

The measures were divided into 8 thematic groups, which allowed for better comparison and evaluation. The following thematic groups were specifically involved: 1) Alternative fuels and clean and energy-efficient vehicles, 2) High quality energy-efficient Passenger Transport, 3) Economic based Demand Management strategies, 4) Mobility Management, Communication and Education, 5) Safety and Security, 6) Mobility services for energyefficient vehicle use, 7) Energy efficient freight distribution, and 8) Innovative Transport Telematics Systems (Civitas Pointer, 2013b).

Within Civitas Plus, the monitoring and methodology of the evaluation of results of implemented innovative measures in cities, as well as harmonization of these processes among the above mentioned five projects / 25 cities was performed by another project called POINTER. The dissemination of outcomes and the presentation of experience were then coordinated by the project VANGUARD.

\subsection{Evaluation process}

The whole process of evaluation of Civitas Plus projects consisted of two parts - evaluation of impacts and evaluation of processes (Civitas Pointer, 2013a). The first of them was more 
quantitative and was based on monitoring and evaluation of relevant indicators of impacts of implemented measures. A template was created with 30 indicators from 5 fields (economy, energy, the environment, society, transport), from which the cities, or institutions which supplied them with expertise for the evaluation, chose the relevant indicators.

The evaluation of the process was then based on the description of barriers, drivers, and performed activities which the cities encountered with individual measures. In this was the data on the impact of measures concerning "talking of what is behind the numbers" were collected. The evaluation was performed at several levels - level of measures, package of measures, the city and the whole edition of CIVITAS Plus.

The evaluation of impacts showed that the measures in the Civitas Plus cities led to increased use of public transport $(3-30 \%$ increase in the number of passengers in these cities), to reduced use of cars (between 4 and 15\%), increased popularity of walking and cycling (between 1 and 4\%; in some cities this increase meant doubled number of cyclists), reduced presence of heavy vehicles in urban areas by $60 \%$, and reduced emissions of $\mathrm{CO}_{2}$ by up to 55\% (Civitas Pointer, 2013a).

\section{ANALYSIS OF BARRIERS AND DRIVERS}

The further text discusses the evaluation of processes, particularly barriers and drivers which influenced the process of the implementation of measures in the cities of Civitas Plus. The following table summarizes the most common barriers and drivers which the cities encountered in different stages of the Civitas projects realization (preparation, implementation, and operation).

Table 1: Overview of main barriers, drivers, and activities of cities under Civitas Plus projects.

\begin{tabular}{|c|c|c|c|}
\hline & Preparatory stage & Implementation stage & Operation stage \\
\hline Barrier & Political, planning & Cultural & Technological, spatial \\
\hline Driver & Problem-related & & Planning, spatial \\
\hline Activity & Involvement of public & Involvement of public & $\begin{array}{c}\text { Political, involvement of public, } \\
\text { technological }\end{array}$ \\
\hline
\end{tabular}

(Source: Brůhová-Foltýnová \& Jordová, 2014a)

\subsection{Political barriers and drivers}

One of the most often mentioned barriers and drivers are the political ones, i.e. related to the decision-making process, funding, production and quality of legislation environment, etc. The most commonly mentioned political barriers / drivers which occurred in European cities of Civitas Plus within the evaluation process are summarized by the following Table. It particularly concerns the lack of integrated long-term planning, but also the formulation of visions and involvement of stakeholders. Since this was mentioned as a barrier by 22 out of 25 cities, it may indicate that those are the problems encountered by both post-communist countries and also countries with a longer democratic tradition. Other barriers mentioned by the cities most often concerned a lack of funds for measures in sustainable mobility (Civitas Plus edition was a large part of the progress in the time of economic crisis) and legislation. These barriers are also closely related to political decision making. 
Table 2: Overview of main political barriers and drivers for cities of Civitas Plus.

\begin{tabular}{|l|c|c|}
\hline \multicolumn{1}{|c|}{ Barrier / driver } & No. of cities: Barriers & No. of cities: Drivers \\
\hline Process of tender - legislation, organization & 17 & 6 \\
\hline $\begin{array}{l}\text { Local elections, personnel changes in town } \\
\text { council }\end{array}$ & 6 & 6 \\
\hline $\begin{array}{l}\text { Communication between relevant town council } \\
\text { departments }\end{array}$ & 8 & 8 \\
\hline Legislation & 18 & 9 \\
\hline $\begin{array}{l}\text { Integrated planning, production of visions and } \\
\text { involvement of stakeholders }\end{array}$ & 22 & 23 \\
\hline Finance & 19 & 17 \\
\hline Cultural differences & 16 & 12 \\
\hline Other & 20 & 0 \\
\hline
\end{tabular}

(Source: Brůhová-Foltýnová \& Jordová, 2014a)

According to the cities of Civitas Plus, the process of integrated planning and involvement of stakeholders was complicated primarily due to low support of politicians, difficult coordination of different stakeholders, low awareness and knowledge of users and transport experts on new traffic measures, or due to the fact that their potential users failed to realize the benefits or even the existence of the measures (Aalborg, Donostia-San Sebastian, Iasi, Ljubljana, Monza, VitoriaGasteiz). Some barriers were caused by a missing common vision, strategy or political documents at the city level. A number of cities openly admitted that the measures were not accepted due to insufficient, cumbersome or exceedingly optimistic planning (Craiova, Gent, Monza, Perugia, Porto, Tallinn, Zagreb). Some problems with communication with key stakeholders were also caused by other reasons which could not be influenced (e.g. schools in Brescia and Utrecht had already been overloaded with other activates). In contrast, support of politicians, acceptance by public or even active demand for measures led to smoother and faster implementation of the measures.

Regarding the financial barriers and drivers, among the mentioned barriers by cities belong: different financial priorities of the cities (low importance for sustainable mobility measures), insufficient financial planning, and economic crisis and lastly the related cuts in city / national budgets. In contrast, drivers included savings of public transport operators / cities that were / were to be reached thanks to the implemented measures. Similarly, the economic crisis motivated people to use public transport, alternative fuels and $\mathrm{P}+\mathrm{R}$ more often.

According to the cities of Civitas Plus, legislation often suffered because of the non-existence of specific measures and missing standardization (lack of national standards). For example, there was missing legislation for production of mobility plans in Aalborg and Coimbra, the implementation of measures in Donostia-San Sebastian and Zagreb was complicated by missing standards for biofuel quality. In addition, legislation limitations complicated and slowed down public procurement in Craiova and Tallinn or led to situations that the use of vehicles for biodiesel was economically disadvantageous (Craiova, Ljubljana). In contrast, the legislation drivers concerned new tools for regulation and integration of visions and measures from the regional level to national level.

Cultural differences include barriers, such as distrust in novelties, conservatism, misunderstanding, reluctance to give up the perception of a car as a status symbol, lack of awareness among users on a given measure and vandalism. A life style independent on cars and the perception of a car as a status symbol are other frequently mentioned cultural barriers of the cities of Civitas Plus (Bologna, Brescia, Donostia-San Sebastian, Gent, Iasi, Monza, 
Tallinn, Ústí nad Labem, Vitoria-Gasteiz). Italian Bologna struggled with a problem to persuade parents and schools to allow children to go to and leave school on their own. In contrast, the drivers included a positive approach of target groups, awareness of stakeholders, willingness to change and interest in the environment.

Signs of changes in mobility culture appeared in Donostia-San Sebastian, new culture and life style is also taking root in Brescia and traffic behaviour preferring sustainable transport is also catching up in Funchal. Inhabitants and experts in Utrecht clearly showed that congestion cannot be solely dealt with by building more road infrastructure and that the smart use of traffic management tools is a better solution.

\subsection{Analysis of barriers and drivers: conclusions}

The experience from the cities of Civitas Plus indicates that the number of barriers which appear in individual stages of the project performance significantly influences the implementation success of traffic measures and their impacts. However, they depend on the type of the measure and location (local/national cultural, legislation and economic context). The success of the measure in the preparatory stage is particularly influenced by political barriers. This stage is also important for technical or RTD traffic measures, since in this stage it is necessary to gain knowledge and expertise. The implementation and operation stages are influenced by organization and planning barriers and financial, technological and spatial barriers.

It was found that targeting the right stakeholders and involving suitable partners has a significantly greater impact on the successful measure implementation than its innovation. Some of the cities from Eastern Europe were confronted with barriers of accepting technological solutions that were locally innovative (but common in Western Europe). Furthermore, they faced technological barriers, e.g. unavailable national / local technology or sufficient number of qualified staff with knowledge of the particular technology.

Public acceptance may seem to be a barrier in the preparatory stage, but should not be an automatic reason to cancel a measure - a successful pilot stage can lead to better acceptance of such a measure and its subsequent implementation.

In the end, most of the barriers were successfully overcome by the cities of Civitas Plus; only 9 measures out of 300 were stopped or cancelled.

\section{HOW TO PREVENT POLITICAL BARRIERS}

The political environment (thus also the number and impacts of political barriers) influences the implementation process of sustainable mobility measures, although its impact is not fatal and consequently does not lead to measure cancellation. The project POINTER identified factors which influence the political environment, and thus indirectly the implementation of innovative traffic measures. The following factors (based on Dobranskyte-Niskota et al., (2007), Kelly et al., (2004), Litman (2011), Wefering et al. (2013)) are concerned:

- Number and structure of policies which are related to transport and their integration and harmonization;

- Existence of integrated transport policies (SUMP - Sustainable Urban Mobility Plan);

- Active use of traffic models;

- Effective long-term planning;

- Stability of local bodies (city councils) - organization of extraordinary community elections;

- Planning of financial resources;

- Planning of human resources;

- Active communication with (local) politicians/representatives; 
- Approaches to public involvement;

- Regular revision of strategies and policies.

The role of these factors are shown in this chapter using examples from the following European cities of Civitas Plus: Aalborg, Gent, and Donostia - San Sebastian.

\subsection{Integration of political documents and strategies in Aalborg}

The Danish city of Aalborg has documents prepared which deal with all relevant aspects of sustainable transport (Civitas Pointer, 2013c). The city tries to harmonize and integrate these documents. Specifically, Aalborg has prepared an overall municipal strategy since 2009 and the land-use plan as well. The main sector document dealing with transport - General Transport Policy - was produced in 1990. It consists of general traffic plans for public transport, cycling and walking. The General Transport Policy is produced so that it would particularly support sustainable transport modes with the focus on mobility, the environment and public health, that it would create a balance between demand for growing mobility and environmental protection, that it would minimize negative impacts of transport and provide accessibility in the city and the whole region.

Aalborg has the Mobility Strategy prepared for 2013 - 2025. Furthermore, the city uses a number of action plans, e.g. action plan for parking, cycling support, road traffic safety, noise reduction, the infrastructure and use of information technologies in transport. In 1994 Aalborg adopted the first Action plan for Traffic and the Environment, which was supported by the Danish Ministry of the Environment.

Furthermore, the city uses a wide range of studies and expert analyses, e.g. a study of the infrastructure in the sea port, conditions for tenders and a new parking scheme. In addition, it reflects national policies and their goals, e.g. the Danish National Strategy on Alternative Fuels. Aalborg organizes campaigns, such as safe ways to schools, safety audits and others.

Transport issues are also included in other sectors and more general urban strategies, such as the Sustainability Strategy. The so-called Aalborg Charter was signed in 1994 in Aalborg (The Charter of European Sustainable Cities and Towns towards Sustainability), which bounds European towns and villages to responsibility in the area of producing sustainable and responsible communities (their higher involvement in Agenda 21). It deals with sustainable development and transport. The Charter was extended to Aalborg's commitments 10 years later.

\subsection{Long-term planning and strategic visions in Gent}

Gent adopted an ambitious urban development strategy called "Climate Plan Neutral Gent 2050". This strategy defines its vision - to become a climatically neutral city by 2050 - which focuses on all aspects of urban functions, not only of transport (Civitas Pointer, 2013c).

A number of different steps were made by the city to meet the objectives of these visions. The Climate Alliance was established in 2009. It associates several Climate Workgroups and supports the exchange of experience within the work groups as well as in between them. A Climate Plan Gent for 2008-2020 (it is an action plan with 105 activities) and an air quality plan were prepared. This plan designs a large number of specific steps, such as tools to support cycling as a non-emission transport mode, "greener" public transport, car-sharing, low-emission zones, traffic management systems, etc.

Furthermore, the city of Gent adopted a mobility plan for the whole city. The first mobility plan was adopted as early as 1997, and then it was followed by a new successful mobility plan in 2003, which significantly influenced mobility in the city. 


\subsection{Regular revision of strategies and policies: Donostia-San Sebastian}

The Spanish city of Donostia-San Sebastian adopted a number of activities and campaigns for support of sustainable mobility, e.g. car-sharing and car-pooling systems, safe routes to school, personal mobility plans, commuting mobility plans, a Road Safety Charter, $30 \mathrm{~km} / \mathrm{h}$ zones, etc.

The city's general strategy is always valid for 10 years, but it is continuously updated. Similarly, the transportation policy and its strategic plan are discussed with stakeholders every four years. The long-term financial plan of the city used to be regularly updated every four years, now it is every year.

\section{CONCLUSION}

The Civitas initiative continues with the current edition of Civitas Plus II, and other projects will be funded by the programme CIVITAS 2020. Therefore, there is an opportunity for Czech cities to get involved in some of the projects and receive support for the implementation of sustainable transport measures. Czech and Slovak cities can get in contact with Civitas through a newly established network of cities CIVINET, whose partial task is to support the exchange of experience of cities with the focus on sustainable mobility support.

The sustainable transport measures supported by the Civitas initiative are both "hard" (i.e. changes or construction of the infrastructure, purchase of vehicle fleet, etc.), and "soft" (particularly focused on informing and raising awareness of the public, better traffic management, car-sharing, car-pooling, and parking policy). Taking into account the innovation aspect of the supported measures, there can be pilot measures for alternative fuels or drives in passenger, personal and public transport and freight transport, or measures using modern information technologies.

In addition, Civitas provides cities with an opportunity to focus on the issue of planning, monitoring and evaluation. The cities can have a Sustainable urban mobility plan prepared, missing data collected, and an important study produced. The fact that the cities find the impacts of the introduced measures and analyse barriers and drivers brings potential for improvement of strategic and long-term urban planning and for a feedback on the functioning of the city and city organizations. Therefore, we can gain experience and prospective potential to reduce the risk of occurrence of barriers described in this text under the realization of the sustainable mobility measures.

\section{ACKNOWLEDGEMENT}

This article was made as a part of the European project CIVITAS POINTER (TREN/FP7TR/219026).

\section{REFERENCES}

Bosetti, S., Brůhová-Foltýnová, H., Jordová, R. et al., 2014. Policy recommendations for EU Sustainable Mobility Concepts based on CIVITAS experience. Freiburg (Germany): ICLEI, Brno (Czech Republic): Transport Research Centre. 68 p. ISBN 978-80-86502-77-9. 
Brůhová-Foltýnová, H., Jordová, R., 2014a. The contribution of different policy elements to sustainable urban mobility. Transportation Research Procedia. Accepted for publication. ISSN 2352-1465.

Brůhová-Foltýnová, H., Jordová, R., 2014b. Inovativní nástroje udržitelné mobility v evropských městských oblastech: zkušenosti s evaluací a role politických bariér [Innovative Tools of Sustainable Mobility in European Urban Areas: Experience with Evaluation and Role of Political Barriers]. In Jandová, V., Mikulová, I., Ličbinský, R. (eds.). VI Czech and Slovak Conference "Transport, Health and the Environment", Brno (Czech Republic), November 10-11, 2014. Brno: Transport Research Centre, pp. 167174. ISBN 978-80-86502-85-4. (in Czech)

CIVITAS POINTER, 2013a. Deliverable 2.6.1, Overview of Evaluation Findings. Transportation Research Group. University of Southampton.

CIVITAS POINTER, 2013b. Deliverable 2.5.1c, Final report on wider implementation of measures. TRG - University of Southampton. Transport Research Centre.

CIVITAS POINTER, 2013c. Deliverable 3.2.2, Final Report on Policy Assessment in the Civitas Plus Programme. Transport Research Centre.

Dobranskyte-Niskota, A., Perujo Mateos Del Parque, A., Pregl, M., 2007. Indicators to Assess Sustainability of Transport Activities - Part 1: Review of the Existing Transport Sustainability Indicator Initiatives and Development of an Indicator Set to Assess Transport Sustainability Performance [online]. ISBN 978-92-79-07802-6 [cited 2014-1031]. Retrieved from: http://publications.jrc.ec.europa.eu/repository/handle/111111111/10416

Kelly, J., Grosvenor, T., Jones, P., 2004. Successful transport decision-making. A project management and stakeholder engagement handbook. VOLUME 1 - Concepts and Tools. GUIDEMAPS consortium.

Litman, T., 2011. Developing Indicators for Comprehensive and Sustainable Transport Planning [online]. Victoria Transport Policy Institute [cited 2014-10-31]. Retrieved from: http://www.vtpi.org/sus_tran_ind.pdf

Wefering, F., Rupprecht, S., Bührmann, S., Böhler-Baedeker, S., 2013. Guidelines. Developing and Implementing a Sustainable Urban Mobility Plan. Rupprecht Consult.

NOTICE: The article was taken over from the proceedings of VI Czech and Slovak Conference "Transport, Health and the Environment" held on 10 - 11 November 2014 in Brno (Czech Republic), upon the decision of the proceedings publisher Transport Research Centre and with the consent of the authors of the article.

With the consent of the authors, the article was adapted on the basis of editing instructions of Transactions on Transport Sciences journal and translated into English language.

The article was produced under the support of the project Transport R\&D Centre (CZ.1.05/2.1.00/03.0064) 